\title{
Supplemental Information: New Particle Formation and Sub-10 nm Size Distribution Measurements during the A-LIFE field experiment in Paphos, Cyprus
}

Table S1: Overview of the CPC settings used during the A-LIFE measurement campaign. Temperature settings were modified from the standard instrument settings for DMA-train channels 0, 2 and 3 to enhance the detection efficiency at the classified 15 mobility diameter, $\mathbf{D}_{\mathbf{p}, \mathbf{m o b} \text {. }}$

\begin{tabular}{lllll}
\hline Channel & $\mathrm{D}_{\mathrm{p}, \text { mob }}(\mathrm{nm})$ & Counter & Working fluid & Settings \\
\hline \hline 0 & 2.2 or 2.5 & TSI 3777 & DEG & $\mathrm{T}_{\text {sat }}=57^{\circ} \mathrm{C}, \mathrm{T}_{\text {con }}=2^{\circ} \mathrm{C}$ \\
1 & 1.8 & PSM & DEG & $\mathrm{T}_{\text {sat }}=81^{\circ} \mathrm{C}, \mathrm{T}_{\text {gr }}=1^{\circ} \mathrm{C}, \mathrm{Q}_{\text {sat }}=1 \mathrm{~L} / \min$ \\
2 & 3.2 & TSI 3776 & n-butanol & $\mathrm{T}_{\text {sat }}=30.1^{\circ} \mathrm{C}, \mathrm{T}_{\text {con }}=0.1^{\circ} \mathrm{C}$ \\
3 & 4.3 & TSI 3776 & n-butanol & $\mathrm{T}_{\text {sat }}=30.1^{\circ} \mathrm{C}, \mathrm{T}_{\text {con }}=0.1^{\circ} \mathrm{C}$ \\
4 & 6 & TSI 3788 & water & $\mathrm{T}_{\text {sat }}=75^{\circ} \mathrm{C}, \mathrm{T}_{\text {con }}=15^{\circ} \mathrm{C}$ (standard) \\
5 & 8 and 10 & TSI 3776 & n-butanol & $\mathrm{T}_{\text {sat }}=39^{\circ} \mathrm{C}, \mathrm{T}_{\text {con }}=10^{\circ} \mathrm{C}$ (standard) \\
\hline
\end{tabular}




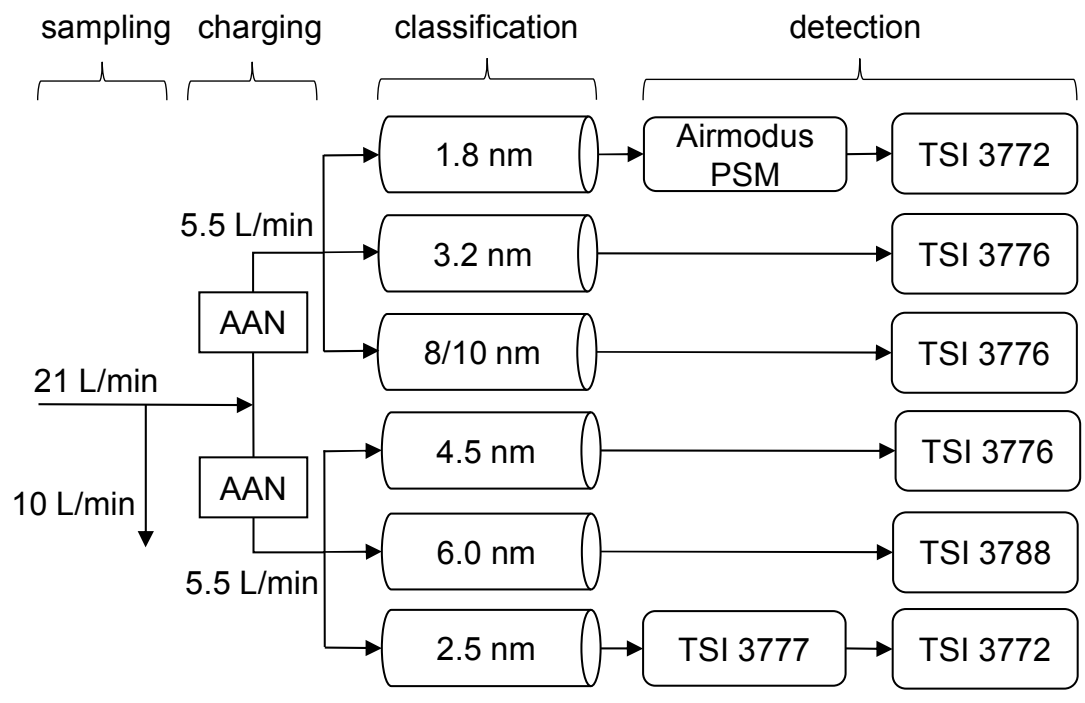

Figure S1: Setup of the DMA-train with six DMAs in parallel operated at fixed voltages followed by CPCs tuned for the detection of the classified particle diameter. The instrumentation is operated in two layers with two CPCs at $1.5 \mathrm{~L} / \mathrm{min}$ inlet flow rate and one at $2.5 \mathrm{~L} / \mathrm{min}$ inlet flow rate each. The set mobility diameter of each size channel is given in the section "classification" in $\mathrm{nm}$. The 25 largest size channel can be operated in alternating mode, i.e. the set mobility diameter alternates between 8 and $10 \mathrm{~nm}$ every 10 seconds. 


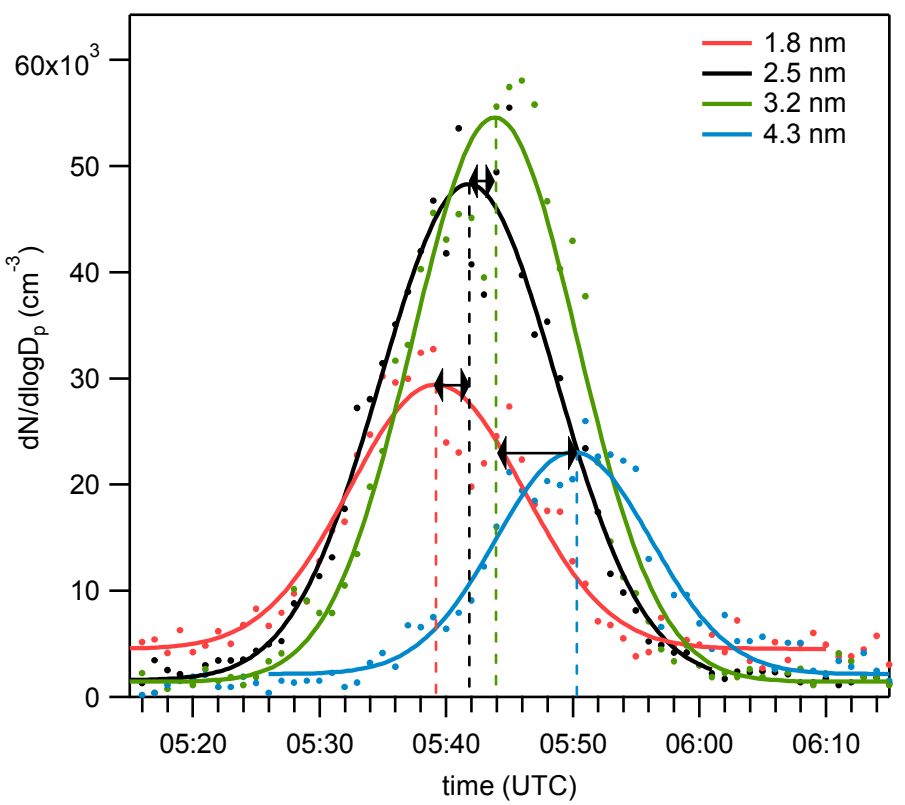

Figure S2: Exemplary demonstration of the DMA-train growth rate analysis from the event on April 16, 2017. The coloured markers 30 show the averaged and inverted DMA-train data in channels 1 - 4. A Gaussian fit is applied to the data of each size channel and the position of the peak gives the time of the mode peak. The sequential appearance of the maximum in each size channel starting from the lowest is illustrated by the black arrows. 


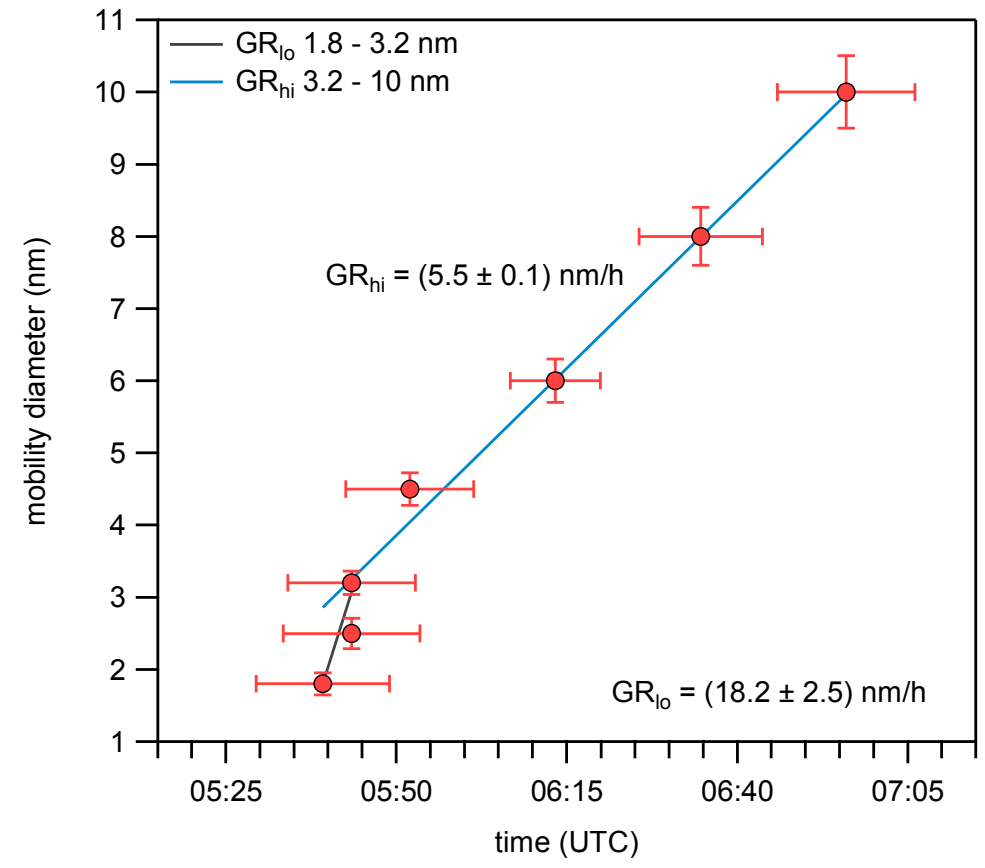

35 Figure S3: The set mobility diameter in each size channel is plotted versus the time of the maximum with the time series of the number size distribution in the background. The growth rate can be directly determined from the slope of the fit to the diameter by applying a linear fit using an orthogonal distance regression. DMA-train growth rates are typically divided into two size intervals which also applies to this ambient data set. In this example from April 16, 2017, an initial growth rate of $18.2 \mathrm{~nm} / \mathrm{h}$ in the lower size interval $(1.8-3.2 \mathrm{~nm})$ is found. The growth rate in the higher size interval $(3.2-10 \mathrm{~nm})$ is $5.5 \mathrm{~nm} / \mathrm{h}$. Note the linear scale on the $\mathrm{y}$ axis. 